\title{
The failing renal graft: A new chapter for CKD patients
}

Rita Leal

Nephrology department, Centro Hospitalar e Universitário de Coimbra, Portugal

Faculty of Medicine, University of Coimbra, Portugal

\section{ABSTRACT}

Returning to dialysis after kidney transplant loss is one of the most difficult transitions for chronic kidney disease patients and their assistant nephrologists. These patients have an increased mortality rate on dialysis and re-transplantation is often difficult due to human leukocyte antigen sensitization narrowing possible donors. The decision on the right timing to start dialysis, vascular access management, optimal immunosuppression withdrawal, graft nephrectomy impact and re-transplant planning are just some of the issues that need to be addressed. However, the optimal care for kidney transplant patients with a failing renal graft is still undefined. In this article we will address this challenging new chapter that affects a growing number of chronic kidney disease patients, with a special focus on allosensitization and immunosuppression withdrawal.

Keywords: graft nephrectomy, HLA, immunosuppressants, kidney graft loss, sensitization

\section{INTRODUCTION}

The last decade has seen a marked improve in short-term kidney transplantation outcomes, but long-term results remain sub-optimal. This has led to an increased prevalence of kidney transplant (KT) patients returning to dialysis worldwide. According to The Portuguese Registry of Dialysis and Transplantation, 2607 patients started dialysis in 2018, of which 174 (7\%) were KT recipients with graft loss.

Returning to dialysis is one of the most difficult transitions for KT patients and their assistant nephrologist, as these patients are extremely complex and face several complications. The preparation to start dialysis, the optimal immunosuppression (IS) withdrawal, the need and impact of graft nephrectomy and the planning for an eventual re-transplant are just some of the issues that need to be addressed.

The main focus of the nephrology community is, understandably, to prolong KT survival, but we need to look beyond the functioning graft and discuss the care of our patients with a failing graft.

\section{THE IMPACT OF RETURNING TO DIALYSIS}

Several authors have analyzed the impact of graft loss on patient morbidity and mortality and the results are discouraging. Mortality rate is three times higher in patients with graft loss than in patients with a functioning graft and is also worse than in incident dialysis patients on KT waiting list. ${ }^{1}$

It is thought that the reason for this higher mortality, mainly cardiovascular and infectious, is influenced by previous and prolonged exposure to IS. However, it has been documented that the early period following IS withdrawal has the highest rates of morbidity and mortality and several other factors might contribute.

A significantly higher percentage of patients start dialysis acutely, by a central venous catheter, and CKD complications such as volume disturbance, mineral bone disease, anemia and malnutrition are less controlled.

The immunological dysfunction associated with chronic kidney disease is especially relevant after graft failure. The abrupt suspension of IS leads to a decrease in T-lymphocytes, and disturbances in B-cell subsets after steroid withdrawal have been documented. ${ }^{2}$ Research has shown that the presence of HLA antibodies increases endothelial dysfunction, not only in renal vasculature but systemically. This promotes inflammation associated with elevated serum cholesterol, low serum albumin and reduction of coronary artery flow rates, all precursors of cardiovascular disease. ${ }^{3}$

Rejection of the failed graft also plays an important role in morbidity and mortality. In addition to the exacerbated pro-inflammatory state that characterizes this rejection, steroid dosing is markedly increased and in severe cases graft nephrectomy is performed, contributing to worse outcomes.

\section{HLA SENSITIZATION AFTER GRAFT LOSS}

There is a clear association between previous exposure to foreign HLA antigens and antibody production, and solid organ transplantation is the most powerful sensitizing event. After graft loss, the risk of developing de novo HLA antibodies exponentially increases and HLA 
sensitization frequently coincides with IS tapering or withdrawing. A study that included 119 patients with graft loss showed a significant increase in HLA sensitization after IS withdrawal, and rapid IS suspension was associated with higher rates of sensitization. ${ }^{4} \mathrm{~A}$ small study of 49 patients showed an increase in sensitization after graft loss that was dependent on the rate at which IS drugs were weaned, with sensitization rates reaching $70 \%$ in rapid IS withdrawal ${ }^{5}$.

Rapid weaning of IS also triggers acute rejection of the failing graft, an independent predictor of alloantibody sensitization and a major cause of refractory anemia with subsequent blood transfusion, potentiating HLA sensitization.

\section{IMMUNOSUPPRESSION WITHDRAWAL}

There is little data to guide clinicians on the optimal management of IS in patients whose kidney graft has failed, and the majority of studies are small and retrospective. The lack of data reflects the lack of consensus: if we look at different transplant units, we will find different approaches, not only between centers but also between nephrologists within the same hospital.

Simply put, there are two possible approaches to IS: continuing low-dose IS, which usually includes low-dose calcineurin inhibitor (CNI) plus low-dose prednisone or rapid $\mathrm{CNI}$ suspension and prednisone taper in under 6 months.

The most consensual potential beneficial effects of maintaining low-dose $\mathrm{CNI}$ and steroids are preservation of residual kidney function, avoidance of overt acute rejection and graft intolerance syndrome and minimization of allosensitization, increasing the access to a subsequent KT. Unfortunately, these benefits might be counterbalanced by an increased risk of metabolic complications, susceptibility to infection, and malignancy.
Single-center studies with small sample sizes have compared both approaches with conflicting results. However, if we analyze recent series that have used CNI and have evaluated HLA sensitization with modern histocompatibility techniques, the results show a significant decrease in HLA sensitization with the same infection rate and mortality risk when maintaining low dose IS. ${ }^{4-7}$ Focusing on older patients with no benefit in subsequent KT, maintaining IS might be deleterious. Steroids and CNI are associated with an increased risk of hypertension, diabetes and dyslipidemia, strong contributors to cardiovascular disease. Although the above-cited studies showed no increased risk of infection or malignancy, older patients or patients with more comorbidities are at a higher risk of developing infections and cancer if maintained on IS -as seen in $\mathrm{KT}$ recipients with maintained graft function.

The British Transplantation Society published the only available guidelines on the management of the failing $\mathrm{KT}^{8}{ }^{8}$ They suggest continuing IS therapy if there is the prospect of re-transplantation within one year of starting dialysis, but the management of other patients is not well defined. The group highlights the importance of pediatric recipients and young adults who are likely to require re-transplantation and in whom the benefit of maintaining IS to decrease de novo allosensitisation might outweight the risks. However, in this group the guidelines are not enlightening, nor do they define an unambiguous strategy. Table 1 summarizes several reported approaches regarding IS withdrawal after KT transplant failure and dialysis initiation.

\section{NEPHRECTOMY OF THE FAILING GRAFT}

Another unsolved issue after graft loss is the impact of graft nephrectomy on patient outcome. The indications for graft nephrectomy include hyper-acute symptomatic rejection, severe infection or neoplasia of the graft. However, there is still a debate on whether leaving the failing graft helps or not in preventing sensitization and increases access to a subsequent KT.

Table 1

Reported methods of immunosuppression withdrawal after graft failure and dialysis initiation. Adapted from Lea-Henry T, Chacko B; Nephrology 23 (2018) ${ }^{9}$

\begin{tabular}{|c|c|c|c|c|}
\hline & Corticosteroid & $\mathrm{CNI}$ or mTor & Antimetabolite & Other \\
\hline Kassakian et al. ${ }^{10}$ & $\begin{array}{l}\text { If retransplant programed within } 12 \text { months, } \\
\text { maintain prednisolone } 5 \mathrm{mg} / \text { day } \\
\text { If no plans to retransplant, no residual renal } \\
\text { function or on dialysis for }>6 \text { months, wean by } \\
1 \mathrm{mg} / \text { month until off }\end{array}$ & Stop immediately & $\begin{array}{l}\text { Wean off over } \\
3 \text { months } \\
\text { Cease if significant } \\
\text { infection. }\end{array}$ & \\
\hline Pham et al. ${ }^{1}$ & $\begin{array}{l}\text { Continue original dose for } 2-4 \text { weeks and then } \\
\text { wean by } 1 \mathrm{mg} / \mathrm{month} \text { until it is ceased. } \\
\text { Can be continued if there is an available live donor } \\
\text { or residual renal function and low risk of } \\
\text { complications }\end{array}$ & $\begin{array}{l}\text { Stop mTOR immediately. } \\
\text { Wean CNI over 4-6 weeks }\end{array}$ & Cease immediately & \\
\hline $\begin{array}{l}\text { British Transplantation } \\
\text { Society Guidelines }{ }^{8}\end{array}$ & Withdraw after $\mathrm{CNI}$, by reducing $1 \mathrm{mg} /$ month & $\begin{array}{l}\text { Gradual taper of } 25 \% \\
\text { dose reduction per week } \\
\text { until off }\end{array}$ & Cease immediately & $\begin{array}{l}\text { Continue IS if there is an available live donor and } \\
\text { retransplantation is expected within } 12 \text { months of } \\
\text { starting dialysis }\end{array}$ \\
\hline Messa et al. ${ }^{11}$ & $\begin{array}{l}\text { Maintain steroid dose for } 1 \text { month, then halve the } \\
\text { steroid dose every month until withdrawn. }\end{array}$ & $\begin{array}{l}\text { Taper and then withdraw } \\
\text { over } 1-3 \text { weeks (if slow } \\
\text { and gradual graft failure) }\end{array}$ & Cease immediately & \\
\hline
\end{tabular}

CNI - calcineurin inhibitors; mTOR - mTOR inhibitors; IS - immunosuppressors 
Many authors have described an immunological benefit of leaving the failed graft, supported by the rapid and early increase of donor-specific antibodies after nephrectomy. Other authors have concluded that the presence of the failed graft limits the ability to detect donor-specific antibodies, which explains "better" sensitization profiles, and that the removal of the graft facilitates rapid IS withdrawal. Either way, and despite the publication of larger studies, the impact of graft nephrectomy on sensitization and immunology remains to be defined.

\section{FINAL COMMENT}

There is a growing recognition of the importance of specific care for KT patients with a failing graft and some centers have developed low-clearance transplant clinics that provide multidisciplinary care with nephrologists, trained nurses, renal dieticians and pharmacists. Unfortunately, this strategy is an exception and for most centers, the optimal management of KT patients returning to dialysis is still undefined.

The number of patients reinitiating dialysis is increasing and represents an independent risk factor for mortality. In selected patients, this can be overcome with re-transplantation, something that has been associated with an $80 \%$ reduction in mortality.

Unfortunately, the access to a subsequent KT is frequently compromised by HLA sensitization and nephrologists are seeing increased waiting times for their young highly sensitized patients. Several measures can be taken to enhance transplantation in these patients, such as living donor and paired donation and desensitization protocols, but they are frequently non-appliable. An attractive perspective is to prevent allosensitization after graft loss, where IS withdrawal may play an important role.

There are no controlled prospective studies to determine the best IS tapering and nephrologists follow individual or center empirical strategies.

With these in mind, our group is developing a prospective randomized study to evaluate the impact of different IS withdrawal strategies of allosensitization and clinical outcomes. We hope that our results will provide fundamental insight into these issues, and eventually standardize care in this important group of patients.

Disclosure of potential conflicts of interest: none declared

\section{References}

1. Pham P-T, Everly M, Faravardeh A, Pham P-C. Management of patients with a failed kidney transplant: dialysis reinitiation, immunosuppression weaning, and transplantectomy World Journal of Nephrology. World J Nephrol [Internet]. 2015 [cited 2019 Jul 24];4(2):148-59. Available from: http://www.wjgnet.com/esps/HelpDesk:http://www.wjgnet.com/esps/helpdesk.aspxURL:http:// www.wjgnet.com/2220-6124/full/v4/i2/148.htmDOl:http://dx.doi.org/10.5527/wjn.v4.i2.148

2. Llinàs-mallol L, Redondo-pachón D, Pére MJ, Raïch-regué $D$, Mir M, Yélamos J, et al. Peripheral blood lymphocyte subsets change after steroid withdrawal in renal allograft recipients: a prospective study. 2019;(October 2018):1-11.

3. Hébert M. Endothelial Dysfunction in Kidney Transplantation. Front Immunol. 2018;9(May):1-8.

4. Augustine JJ, Woodside KJ, Padiyar A, Sanchez EQ, Hricik DE, Schulak JA. Independent of nephrectomy, weaning immunosuppression leads to late sensitization after kidney transplant failure. Transplant J [Internet]. 2012 Oct 15 [cited 2019 Jun 18];94(7):738-43. Available from: http://www. ncbi.nlm.nih.gov/pubmed/22955228

5. Casey MJ, Wen X, Kayler LK, Aiyer R, Scornik JC, Meier-Kriesche HU. Prolonged immunosuppression preserves nonsensitization status after kidney transplant failure. Transplantation. 2014;98(3): 306-11.

6. Woodside KJ, Schirm ZW, Noon KA, Huml AM, Padiyar A, Sanchez EQ, et al. Fever, infection, and rejection after kidney transplant failure. Transplantation. 2014;97(6):648-53.

7. Singh P, Filippone EJ, Colombe BW, Shah AP, Zhan T, Harach M, et al. Sensitization trends after renal allograft failure: the role of DQ eplet mismatches in becoming highly sensitized. Clin Transplant [Internet]. 2016 Jan [cited 2019 Jul 23];30(1):71-80. Available from: http://www.ncbi.nlm. nih.gov/pubmed/26529289

8. Management of the Failing Kidney Transplant British Transplantation Society Guidelines [Internet]. 2014 [cited 2019 Jul 15]. Available from: www.bts.org.uk

9. Lea-Henry T, Chacko B. Management considerations in the failing renal allograft. Nephrology. 2018;23(1):12-9.

10. Kassakian CT, Ajmal S, Gohh RY, Morrissey PE, Bayliss GP. Immunosuppression in the failing and failed transplant kidney: optimizing outcomes. Nephrol Dial Transplant. 2016;31(8):1261-9.

11. Messa P, Ponticelli C, Berardinelli L. Coming back to dialysis after kidney transplant failure. Nephrol Dial Transpl [Internet]. 2008 [cited 2019 Jul 24];23:2738-42. Available from: https://academic. oup.com/ndt/article-abstract/23/9/2738/1866750

\section{Correspondence to:}

Rita Leal, MD

Nephrology department, Centro Hospitalar e Universitário de Coimbra Coimbra, Portugal

E-mail: rita.gcleal@gmail.com 